\title{
Geochemical Evaluation of Fluid- Rock Interactions between Niobrara Formation and Alkaline Fracturing Fluid during Well Shut In, Denver- Julesburg Basin, CO, USA: A 30-Day Experimental Study \\ OLIVIA TERRY ${ }^{1}$, DEREK CARO ${ }^{2}$, JANET DEWEY ${ }^{2}$ AND JOHN P. KASZUBA ${ }^{2}$ \\ ${ }^{1}$ ConocoPhillips \\ ${ }^{2}$ University of Wyoming \\ Presenting Author: oliviaterry95@gmail.com
}

Flowback and produced water from hydraulically-fractured reservoirs is typically sampled and analyzed after hydraulic fracturing fluid is injected into the reservoir and the well has been shut in for weeks. Analysis of these fluids demonstrates that geochemical reaction between reservoir rock and fracturing fluid is limited in the weeks to months after production begins. However, geochemical reactions between reservoir rock and injected fluid are known to occur on the order of a few days, a timeframe less than the typical shut-in period of a hydraulicallyfractured reservoir. Two laboratory experiments were performed to analyze the potential for geochemical reactions between reservoir rock and injected fracturing fluid within the timescale of a shut-in well. The hydrothermal experiments replicated injection of hydraulic fracturing fluid into the B-Bench of the Cretaceous Niobrara Formation, Denver-Julesburg Basin, Colorado, USA, an actively producing unconventional reservoir. One experiment reacted chalk core $(95 \%$ calcite, $3 \%$ quartz, $2 \%$ clay and pyrite) and a second experiment reacted marl core $(65 \%$ calcite, $20 \%$ quartz, $15 \%$ clay and trace pyrite and feldspars) each experiment reacted core with alkaline hydraulic fracturing fluid $(\mathrm{pH}=10.1)$ at reservoir conditions of $113^{\circ} \mathrm{C}$ and $27.5 \mathrm{MPa}$ for $\sim 35$ days. Aqueous samples were collected from the ongoing experiments to evaluate changes in composition of major, minor, and trace ions, total dissolved total inorganic carbon, and ex-situ $\mathrm{pH}$. Geochemical calculations were conducted to determine insitu $\mathrm{pH}$, activities of aqueous species, and mineral saturation states using chemical analyses of these water samples. Temporal evolution of aqueous geochemistry and thermodynamic evaluation of both experiments indicate 1) $\mathrm{pH}$ neutralization to 6.6-7 by carbonate mineral reactions within 6 hours; 2) nonstoichiometric dissolution of $\mathrm{Mg}$-calcite and formation of secondary calcite within 200 hours; 3) aluminosilicate mineral dissolution within 50-100 hours; and 4) secondary clay mineralization after 50-100 hours. However, ion-milled SEM and optical microscopy provided no evidence of carbonate or silicate mineral reaction. While aqueous geochemical evolution suggests fluid-mineral reactions between alkaline hydraulic fracturing fluid and Niobrara Formation chalk and marl in the short-term (less than $\sim 30$ days), secondary mineralization is limited. 